\title{
Validation of Ti(III) as a Reducing Agent in the Chemiluminescent Determination of Nitrate and Nitrite in Seawater
}

\author{
Rhea K. Foreman ${ }^{1 *}$, Mariona Segura-Noguera ${ }^{1,2}$, David M. Karl ${ }^{1}$ \\ ${ }^{1}$ Daniel K. Inouye Center for Microbial Oceanography: Research and Education, University of \\ Hawaii at Manoa, 1950 East-West Road, Honolulu, Hawaii 96822, USA \\ ${ }^{2}$ Present address: ChELSI Institute, Advanced Biomanufacturing Centre, Department of \\ Chemical and Biological Engineering, The University of Sheffield, Mappin Street, Sheffield S1 \\ 3JD, United Kingdom \\ *corresponding author \\ Email: rforeman@hawaii.edu
}

Figure count: 5

Table count: 2

Supplementary Information: Appendix A.pdf

\begin{abstract}
Titanium (III) trichloride is validated here for the quantitative conversion of all nitrate plus nitrite in seawater to nitric oxide gas, thereby providing an alternative to the typically used reducing agent, ferrous ammonium sulfate plus ammonium molybdate, in the chemiluminescent detection of nitrate plus nitrite at the nanomolar level. We find that both $\mathrm{Fe}(\mathrm{II})+\mathrm{Mo}(\mathrm{VI})$ and $\mathrm{Ti}(\mathrm{III})$ methods yield identical results for standards and seawater samples over a validated concentration range of 1 to $1000 \mathrm{nM}$, and are both in agreement with traditional colorimetric results. Benefits of the $\mathrm{Ti}(\mathrm{III})$ reduction chemistry are: simpler preparation, decreased ammonium contamination in a laboratory that measures low-level nutrients, $30 \%$ reduction of the sulfuric acid catalyst, and a higher sample through-put. Most importantly, though, this work can be considered the first step on a path toward a much-needed, direct measurement of dissolved organic nitrogen concentrations, as has already been achieved for dissolved organic carbon.
\end{abstract}




\section{Introduction}

In natural waters, the quantification of nitrate $\left(\mathrm{NO}_{3}{ }^{-}\right)$plus nitrite $\left(\mathrm{NO}_{2}{ }^{-}\right)$concentration (here forth referred to as $[\mathrm{N}+\mathrm{N}]$ ) is typically done colorimetrically, in which case detection limits are 15-30 $\mathrm{nM}$ at best for segmented flow methodologies (e.g. Karl et al., 2001; Segura-Noguera et al., 2011). However, $[\mathrm{N}+\mathrm{N}]$ in extremely oligotrophic marine settings is typically 1 to $10 \mathrm{nM}$ in surface water (Garcia et al., 2014), necessitating a more sensitive method to quantify this basic nutrient in the uppermost portion of approximately one-third of the world's oceans.

Recognizing the need for a lower detection limit of [N+N], Garside (1982) applied the (Cox, 1980) chemiluminescent (CL) method to seawater in which $[\mathrm{N}+\mathrm{N}]$ are chemically reduced to nitric oxide (NO) gas and subsequently detected downstream via a highly selective, chemiluminescent reaction with ozone to produce excited-state nitrogen dioxide gas $\left(\mathrm{NO}_{2}\right)$. The number of photons detected by $\mathrm{NO}_{2}$ returning to ground state is linearly proportional to the amount of NO in the sample gas stream, and hence the integrated signal output varies linearly with sample concentration. Reduction equations are as follows (Cox, 1980):

$$
\begin{gathered}
\mathrm{NO}_{3}{ }^{-}+4 \mathrm{H}^{+}+3 \mathrm{e}=\mathrm{NO}+2 \mathrm{H}_{2} \mathrm{O} \\
\mathrm{NO}_{2}{ }^{-}+2 \mathrm{H}^{+}+\mathrm{e}=\mathrm{NO}+\mathrm{H}_{2} \mathrm{O}
\end{gathered}
$$

Because nitrite produces NO under much milder reducing conditions than nitrate does, a careful selection of reducing agent can result in the determination of either nitrite alone, or nitrite plus nitrate. For seawater, it is typical to use sodium iodide and glacial acetic acid to reduce nitrite alone and ferrous ammonium sulfate, ammonium molybdate and concentrated sulfuric acid to reduce $[\mathrm{N}+\mathrm{N}]$ together (Garside, 1982). These reducing reagents have been used extensively to measure low level $[\mathrm{N}+\mathrm{N}]$ at Station ALOHA, the location of the Hawaii Ocean Time-series (HOT) (e.g. Dore and Karl, 1996) and during oligotrophic periods of the Bermuda Altlantic Time-series Study (BATS) (e.g. Lipschultz, 2001).

One drawback of using $\mathrm{Fe}(\mathrm{II})+\mathrm{Mo}(\mathrm{VI})$ as reducing agents is that the reagents are both obtained as ammonium salts. Laboratory groups that are interested in the determination of $[\mathrm{N}+\mathrm{N}]$ are also likely to want to measure ammonium $\left(\mathrm{NH}_{4}{ }^{+}\right)$, especially as more information comes to light about its critical role in the marine nitrogen cycle (e.g. Francis et al., 2007), and as liquid waveguide capillary cell methods provide applicably low detection limits (Holmes et al., 1999; Zhu et al., 2014). Since one of the biggest challenges of $\mathrm{NH}_{4}^{+}$measurements is background contamination, an obvious step is to remove significant sources of ammonium from 
the analytical environment. Another implication of using ammonium salts for the reduction of $[\mathrm{N}+\mathrm{N}]$ is that it precludes coupled measurements of $[\mathrm{N}+\mathrm{N}]$ and dissolved organic nitrogen (see Section 3.4.1.) due to the excessive contamination by ammonium.

Titanium (III), supplied as $\mathrm{TiCl}_{3}$, is ammonium-free and known to reduce $[\mathrm{N}+\mathrm{N}]$, but, unlike the $\mathrm{Fe}(\mathrm{II})+\mathrm{Mo}(\mathrm{VI})$ method, it is capable of reducing other nitrogen-containing compounds such as nitrate esters and nitramines (Awad and Hassan, 1969). Unexpectedly, a study by Yang et al. (1997) presented the effects of reducing agents on the recovery of $[\mathrm{N}+\mathrm{N}]$ from plasmas of pig and dog and found lower recoveries using Ti(III) than using Fe(II)+Mo(VI). Also confusing is work by Aoki and Wakabayashi (1995) and Aoki et al. (1997), who used $\mathrm{TiCl}_{3}$ in a flow injection method coupled to the $\mathrm{CL}$ detection of $[\mathrm{N}+\mathrm{N}]$ : they obtained a greater $\mathrm{CL}$ response from nitrite than nitrate, suggesting that the nitrite/nitrate ratio must be known to provide an accurate determination of $[\mathrm{N}+\mathrm{N}]$. We suspect this to be the result of low reaction temperature, but validation is needed. To our knowledge, no data have been published, nor methods validated, using $\mathrm{Ti}(\mathrm{III})$ as a reducing agent for the $\mathrm{CL}$ detection of $[\mathrm{N}+\mathrm{N}]$ in seawater.

Vanadium (III) is another ammonium-free reducing agent that has been shown to yield equivalent results to $\mathrm{Fe}(\mathrm{II})+\mathrm{Mo}(\mathrm{VI})$ (Braman and Hendrix, 1989; Yang et al., 1997), but is not considered here because of difficult reagent preparation as well and as its high toxicity. Here we validate the use of $\mathrm{Ti}(\mathrm{III})$ as a reducing agent in the $\mathrm{CL}$ determination of $[\mathrm{N}+\mathrm{N}]$ in seawater and provide an extensive comparison to the $\mathrm{Fe}(\mathrm{II})+\mathrm{Mo}(\mathrm{VI})$ method, as well as to traditional colorimetric analyses. We find that $\mathrm{Fe}(\mathrm{II})+\mathrm{Mo}(\mathrm{VI})$ and $\mathrm{Ti}(\mathrm{III})$ give identical results for both standards and seawater samples ranging in concentration from 1 to $1000 \mathrm{nM}$, and are both in agreement with colorimetric results. In addition, both reducing agents yield the same precision, accuracy, and detection limit for $[\mathrm{N}+\mathrm{N}]$ in seawater.

\section{Methods}

\subsection{Analytical setup}

The overall flow path (Appendix A) is based on the assembly of Cox (1980) and Garside (1982), with additional steps taken to purify the extracted sample gas. A reaction chamber was fabricated by Ace Glass, Inc. (custom part \#D100077) from an upside-down, $125 \mathrm{~mL}$ Erlenmeyer flask fit with a PTFE stopcock at the base, two \#7-threaded ports at the top for reagent and sample injection, and a degassing pathway for the flow-through of carrier gas. 
Samples and reagents are injected into the reaction chamber using manual injection and selection valves, respectively (Upchurch Scientific models V-541 and V-341). Reducing reagents are injected into the reaction chamber first and allowed to react for $\sim 1$ minute to purge background $[\mathrm{N}+\mathrm{N}]$, after which the sample is injected to a zero-blank environment. The carrier gas, UltraHigh Purity (UHP) Argon, is regulated with a needle valve upstream of the reaction chamber, bubbles through the sample/reagent mixture via a medium-porosity sintered glass frit, then exits with the entrained sample gas through a side arm at the top of the chamber at a flow rate of approximately $600 \mathrm{~mL} / \mathrm{min}$.

In-line purification of the sample gas is crucial for maintaining a stable baseline, clean detector, and high sensitivity. Accordingly, the sample gas passes sequentially through the following: an acid and water vapor trap, a sodium carbonate column, a sample gas dryer, and a needle valve, before entering the detector.

The acid/water vapor trap consists of a gas washing bottle fitted with an extra coarse glass frit $(60 \mathrm{~mL}$ size for the $\mathrm{Fe}(\mathrm{II})+\mathrm{Mo}(\mathrm{VI})$ method and $125 \mathrm{~mL}$ size for the Ti(III) method) filled two-thirds full with $6 \mathrm{~N}$ ACS Grade sodium hydroxide and placed in an ice water bath. This first purification step neutralizes most of the acid vapor and theoretically dries the sample gas to a dew point of $0^{\circ} \mathrm{C}$.

The sodium carbonate column provides the final clean-up of acid vapors from the sample gas and will also collect mist or droplets of water. The glass column is $18.5 \mathrm{~cm}$ long by $1.5 \mathrm{~cm}$ I.D. with a 14/20 standard glass taper on each end. It is filled with $20 \mathrm{~g}$ of sodium carbonate mixed with $9 \mathrm{~g}$ of $1 \mathrm{~mm}$-sized quartz chips to prevent clogging; glass wool is used as a stopper on each end of the carbonate mixture. The packed column is kept in a $60^{\circ} \mathrm{C}$ drying oven at least overnight and until use.

Water vapor in the sample gas is the primary cause for decreased sensitivity in the CL nitrogen detector, as energy from excited $\mathrm{NO}_{2}$ is dissipated by collisional degradation with $\mathrm{H}_{2} \mathrm{O}$ instead of through the emission of photons (Mark Homan, PAC, LP, pers. comm.). Hence, we employ a sample gas dryer consisting of a Nafion membrane (Permapure \#MD-070-48P-2) with countercurrent flow of dried house air (using a Drierite canister, \#26840) as the final step in the purification of sample gas.

The extracted NO gas is detected by CL using an Antek model 7090 nitrogen detector set at a sensitivity of 25 , high gain, and $750 \mathrm{~V}$ on the photo-multiplier tube. Flow-through of 
sample gas is facilitated by a vacuum pump on the exit of the detector (Vacuubrand MZ-2C-NT) and is required to obtain low detection limits. Needle valves regulating (1) argon supply to the reaction chamber and (2) exit of sample gas to the detector are balanced to create a slightly positive pressure in the sample reaction chamber (such that the solution can be drained after every analysis). Research Grade 5 oxygen (99.999\% purity) is supplied directly to the detector at $40 \mathrm{psi}$ for the generation of ozone. Voltage signal is output to a PeakSimple Chromatography Data System from SRI Instruments (Model 333) and processed by their freely available PeakSimple Chromatography Integration Software. All peaks are manually selected. Total run time is 2.8 minutes per sample injection, including reaction time of reagents.

\subsection{Standards and Reagents}

High purity, 18.2 M $\Omega-\mathrm{cm}$, de-ionized water (DI) was used for bottle washing and the preparation of all standards and reagents; it consistently has undetectable $[\mathrm{N}+\mathrm{N}](<1 \mathrm{nM})$ when analyzed as a sample. A $10,000 \mu \mathrm{M}$, primary nitrate standard was made from high purity $\mathrm{KNO}_{3}$ powder (Fisher P838-100); it is dried for at least 48 hours at $50^{\circ} \mathrm{C}$ then cooled to room temperature in a desiccator before being weighed. The primary standard is preserved with $0.1 \%$ chloroform and is kept in the dark at room temperature for up to one year. Secondary standards of $100 \mu \mathrm{M} \mathrm{KNO}{ }_{3}$ are made weekly and stored in the refrigerator. Working standards used for calibration of the nitrogen detector are made fresh daily. The Wako CSK standard nitrate solution at $40.0 \mu \mathrm{M} \mathrm{N}$ (Wako \#037-10241) is used as a reference standard and is diluted into our working range daily. All standards and reagents are prepared in glass volumetric flasks.

The sulfuric acid, ferrous ammonium sulfate hexahydrate and ammonium molybdate tetrahydrate used are all ACS Grade. Powders of $\mathrm{TiCl}_{3}$ are available from a limited number of suppliers, but we discarded its use because its pyrophoric nature presents a substantial safety hazard. Premade $\mathrm{TiCl}_{3}$ solutions contain dilute hydrochloric acid $(\mathrm{HCl})$ from every known supplier. We use Acrōs Organics $20 \%$ (w/v) $\mathrm{TiCl}_{3}$ in $2 \mathrm{~N} \mathrm{HCl}$ (\#39562), which contains a lower $\mathrm{HCl}$ concentration $(2 \mathrm{~N})$ and higher $\mathrm{TiCl}_{3}$ concentration compared to other currently available options. The high vapor pressure of $\mathrm{HCl}$ causes breakthrough of acid vapors on the sample extraction line and has a negative impact on signal stability; therefore, minimizing $\mathrm{HCl}$ content maximizes signal integrity. 
Reagent concentrations and volumes using $\mathrm{Fe}(\mathrm{II})+\mathrm{Mo}(\mathrm{VI})$ as a reducing agent follow the exact proportions used by Cox (1980) and Garside (1982): a $10 \mathrm{~mL}$ sample is added to $10 \mathrm{~mL}$ concentrated sulfuric acid, $2 \mathrm{~mL}$ of $4 \%$ ferrous ammonium sulfate hexahydrate and $2 \mathrm{~mL}$ of $2 \%$ ammonium molybdate tetrahydrate. The Fe(II) and Mo(VI) reagents should be prepared fresh daily for best performance.

Reagent concentrations and volumes using Ti(III) as a reducing agent are as follows: a 10 $\mathrm{mL}$ sample is added to $7 \mathrm{~mL}$ of concentrated sulfuric acid and $2 \mathrm{~mL}$ of $4 \%(\mathrm{w} / \mathrm{v}) \mathrm{TiCl}_{3}$. Heat provided by the hydration of sulfuric acid results in temperatures of reaction of $\sim 95^{\circ} \mathrm{C}$ once the sample is injected. The $4 \% \mathrm{TiCl}_{3}$ solution is made in small batches $(200 \mathrm{~mL})$ and used for one to two days only. "Mother bottles" of $\mathrm{TiCl}_{3}$ from the supplier are best maintained by purging the headspace with argon (or another inert gas) after each opening; in doing so, we have not noticed any degradation (i.e. precipitation of $\mathrm{TiO}_{2}$ ) over the course of one year.

\subsection{Seawater Samples}

Seawater samples used for the comparison of reducing agents were collected from Station ALOHA, located $100 \mathrm{~km}$ north of Oahu, Hawaii, at $22^{\circ} 45^{\circ} \mathrm{N}, 158^{\circ} \mathrm{W}$, during the HOE-BOE I expedition aboard the R/V Kilo Moana (cruise \#1409). Seawater was collected in a depth range 5-150 m using a CTD rosette of 24 ten-liter Niskin bottles. Unfiltered samples were immediately stored in $500 \mathrm{~mL}$ high-density polyethylene bottles in a $-4^{\circ} \mathrm{C}$ freezer (Dore et al., 1996) and then thawed overnight at lab temperature $\left(20^{\circ} \mathrm{C}\right)$ prior to analysis.

\subsection{Colorimetry Data}

For comparison to the $\mathrm{CL}$ data, colorimetric analyses for $[\mathrm{N}+\mathrm{N}]$ have also been made on our seawater samples following Strickland and Parsons (1972) adapted for segmented flow on a SEAL (formerly branded Bran Luebbe) AutoAnalyzer III. In this method, nitrate is quantitatively reduced to nitrite in a copperized cadmium reduction column buffered with ammonium chloride at $\mathrm{pH}$ 8.5. Nitrite is subsequently reacted with a mixed color reagent consisting of phosphoric acid, sulfanilamide and N-(1-Naphthyl)ethylenediamine dihydrochloride (NEDA). Light absorption due to the formation of an azo dye is then detected spectrophotometrically at a wavelength of $550 \mathrm{~nm}$. This method has a limit of quantification of $\sim 40 \mathrm{nM}[\mathrm{N}+\mathrm{N}]$, an average 
repeatability of $\quad 0.4 \%$ and long-term accuracy within $2 \%$ (http://hahana.soest.hawaii.edu/hot/methods/inuts.html).

\section{Results and Discussion}

\subsection{Reagent Optimization}

Titanium (III) chloride (in $2 \mathrm{~N} \mathrm{HCl}$ ) can be used alone to reduce $[\mathrm{N}+\mathrm{N}]$ in seawater. However, heat and acid are needed to catalyze the reduction reaction so that the NO gas is generated rapidly and can be measured downstream immediately. Concentrated sulfuric acid is typically used as the acid catalyst in the CL detection of [N+N] (Cox, 1980; Garside, 1982; Aoki and Wakabayashi, 1995) because (1) it is highly exothermic upon hydration, thereby providing a reliable and consistent reaction temperature without the need for an external heat source, and (2) it has a low vapor pressure. We gave much consideration to the use of hydrochloric acid $(\mathrm{HCl})$ as the acid catalyst since it is much safer in the case of acute exposure, and, unlike sulfuric acid, it does not react with $\mathrm{TiCl}_{3}$. In early testing, we found that using $\mathrm{HCl}$ results in high quality sample peaks given an externally applied heat source (data not shown), but its high vapor pressure negatively affected the sample extraction line, caused an intolerable amount of baseline instability, and caused corrosion in the reaction chamber of the detector. As a result, sulfuric acid remained the chosen catalyst. If one pursued the use of $\mathrm{HCl}$, we recommend a smaller reaction vessel with a very steady heat source (to avoid sharp changes in temperature) and the addition of a condenser before the acid trap to release large amounts of acidic condensation.

The following objectives were considered with respect to optimizing reagent volumes and concentration of the Ti(III) reagent: (1) effective scrubbing of background $[\mathrm{N}+\mathrm{N}]$ contained in the sulfuric acid, (2) quality of peaks, (3) stability of the baseline, and (4) the ability to produce a resolvable peak from a $2 \mathrm{nM} \mathrm{KNO}_{3}$ standard.

\subsubsection{Undiluted $\mathrm{TiCl}_{3}$}

Our first approach was to use the $\mathrm{Ti}(\mathrm{III})$ reagent as provided by the commercial supplier $\left(20 \% \mathrm{TiCl}_{3}\right.$ in $\left.2 \mathrm{~N} \mathrm{HCl}\right)$; this makes preparation simple and also helps to preserve the assay of Ti(III) (by not introducing oxygen-rich DI water). In this scenario, we found peak shape and signal counts to be optimized when using $6 \mathrm{~mL}$ of concentrated sulfuric acid per $10 \mathrm{~mL}$ sample injection. Higher amounts of sulfuric acid resulted in greater baseline noise with no 
improvement in peak counts. Lower amounts of sulfuric acid (i.e. $\leq 5 \mathrm{~mL}$ ) produced broad peaks and slightly decreased counts, both of which are detrimental to the detection limit. Using $1 \mathrm{~mL}$ of $20 \%(\mathrm{w} / \mathrm{v}) \mathrm{TiCl}_{3}$ solution (in $2 \mathrm{~N} \mathrm{HCl}$ ) per sample injection resulted in quality peaks at both high and low nitrate concentrations; $2 \mathrm{~mL}$ does not improve peak shape or counts, but can increase baseline noise, presumably due to increased breakthrough of $\mathrm{HCl}$ vapor. Using $0.5 \mathrm{~mL} \mathrm{TiCl} \mathrm{T}_{3}$ reagent improves both peak height and count rate and decreases baseline noise; however, there is incomplete reaction with the sulfuric acid due to low reaction temperature, meaning the sulfuric acid $[\mathrm{N}+\mathrm{N}]$ blank is not sufficiently purged and there is carryover to sample peaks, as observed by overestimates of standard concentrations at 2-4 $\mathrm{nM}$ nitrate. Ultimately, using the $\mathrm{TiCl}_{3}$ reagent "undiluted" created an undesirable scenario in which reagent optimization was largely focused on minimizing baseline noise instead of evaluating peak quality.

\subsubsection{Diluted $\mathrm{TiCl}_{3}$}

Using diluted $\mathrm{TiCl}_{3}$ stabilizes the $\mathrm{CL}$ baseline (by minimizing $\mathrm{HCl}$ vapor in the sample extraction line) and allowed us to focus on sample peak shape. Sample peaks in the CL detection of $[\mathrm{N}+\mathrm{N}]$ are shaped by the kinetics of chemical reaction and degasification of NO gas. Assuming the reaction follows a 'simple rate law', we would expect the sample peak to display a steep front followed by an exponential decay and, in fact, we do observe the peaks to be asymmetrical by nature (with the exception of very small peaks obtained from $[\mathrm{N}+\mathrm{N}]$ under $\sim 10$ $\mathrm{nM}$ ). Therefore, evaluating peak quality on the basis of symmetry is not applicable and instead we evaluate peak quality according to peak width at $50 \%$ peak height.

Background $[\mathrm{N}+\mathrm{N}]$ in the concentrated sulfuric acid, if present, is most effectively purged by adding $2 \mathrm{~mL}$ of the $\mathrm{TiCl}_{3}$ reagent, as this provides a high enough reaction temperature to minimize the purge time to less than 1 minute. The optimal volume of sulfuric acid to be used for $10 \mathrm{~mL}$ sample injections was then determined by setting the Ti(III) reagent to $2 \mathrm{~mL}$ of $5 \%$ (w/v) $\mathrm{TiCl}_{3}$ (as suggested by Cox, 1980) and evaluating peak quality over a range of sulfuric acid volumes. Figure 1a shows that peak widths for a $200 \mathrm{nM} \mathrm{KNO}_{3}$ standard decrease as the sulfuric acid volume increases from 5 to $7 \mathrm{~mL}$; it is important to note, though, that integrated peak counts do not change, meaning only signal shape is changing, not recovery/reaction of nitrate.

With the optimal volume of sulfuric acid set to $7 \mathrm{~mL}$, peak quality was evaluated over a

$\mathrm{TiCl}_{3}$ concentration range of $1-6 \%$ (Figure 1b). Peak widths of a $200 \mathrm{nM} \mathrm{KNO} 3$ standard 
decrease as $\mathrm{TiCl}_{3}$ increases up to $4 \%$, at which point, higher concentrations yield no additional improvement in peak shape. Again, integrated count rates do not change over the tested concentration range, indicating the insensitivity of this method to exact reagent volumes and concentrations.

In summary, using $2 \mathrm{~mL}$ of $4 \% \mathrm{TiCl}_{3}$, and $7 \mathrm{~mL}$ of concentrated sulfuric acid, the final concentration of $\mathrm{TiCl}_{3}$ in the reagent plus sample mixture is $0.4 \%$. This abundance is in gross excess of that needed to simply reduce the nitrate (see section 3.4.1.) because Ti(III) is also oxidized by oxygenated water used for dilution, sulfuric acid, the injected sample, and through aging, but primarily it is needed to create a high chemical potential and fast reaction rate. Similar to our reagent parameters, Cox (1980) suggested using $5 \mathrm{~mL}$ of concentrated sulfuric acid and $1 \mathrm{~mL}$ of $5 \%(\mathrm{w} / \mathrm{v}) \mathrm{TiCl}_{3}$ for a $5 \mathrm{~mL}$ sample, although no data from $\mathrm{Ti}(\mathrm{III})$ work were presented.

\subsection{Method Validation}

At a sensitivity setting of ' 25 ' and high gain on the Antek 7090 CL nitrogen detector, the linear working range spans 3 orders of magnitude, from $\sim 1 \mathrm{nM}$ to $2 \mu \mathrm{M}[\mathrm{N}+\mathrm{N}]$, which translates to $0.14-280 \mathrm{ng}$ of injected nitrogen from a $10 \mathrm{~mL}$ sample. It is worth noting that at the lowest sensitivity setting of the detector, the linear working range extends to $>40 \mu \mathrm{M}[\mathrm{N}+\mathrm{N}]$.

Figure 2 shows a typical calibration curve for low $[\mathrm{N}+\mathrm{N}]$ concentrations. It is evident that there is no matrix effect since solutions prepared in de-ionized water fall on an identical calibration curve as solutions prepared in seawater. There is likewise no resolvable difference between the CL calibration obtained from nitrate versus nitrite, confirming previous work exploring Ti(III) as a reducing reagent (Awad and Hassan, 1969). Additional examples of nitrite recovery are presented in Table 2 , including 3 nitrite standard solutions and one seawater sample known to contain $331 \mathrm{nM}$ nitrite out of a total $[\mathrm{N}+\mathrm{N}]$ of $\sim 370 \mathrm{nM}$. Recovery of nitrite in all cases is accurate within $2 \sigma$ reproducibility limits (see below). Also, using the Wako CSK standard nitrite solution, a $40 \mathrm{nM}$ nitrite reference standard was prepared fresh and analyzed on 5 separate days, yielding an average value of $39.8 \mathrm{nM} \pm 0.4(1 \sigma ; \mathrm{n}=11)$.

Repeatability ( $R$, replicate measurements of the same sample, same day) varies greatly over the 'high-sensitivity' working range (Table 1), as to be expected when spanning 3 orders of magnitude. Repeatability, expressed as $\mathrm{nM}[\mathrm{N}+\mathrm{N}]( \pm 1 \sigma)$, ranges from $\pm 0.15 \mathrm{nM}$ (or $7 \%$ ) at 2 
$\mathrm{nM}$, improves to $\pm 3.5 \mathrm{nM}$ (or $0.4 \%$ ) at $1000 \mathrm{nM}$, and is best fit by the following power law (Figure 3):

$$
\mathrm{R}_{\text {sample }}=0.084 \cdot\left(\mathrm{nM}[\mathrm{N}+\mathrm{N}]_{\text {sample }}\right)^{0.53}
$$

The above curve is constrained by 6 data points for solutions of $\mathrm{KNO}_{3}$ prepared in DI water and 4 data points for natural seawater samples. Based on repeatability of the lowest standard ( $2 \mathrm{nM}$ $\left.\mathrm{KNO}_{3}\right)$, the limit of detection $(3 \sigma)$ is $0.45 \mathrm{nM}$ and the limit of quantification $(10 \sigma)$ is $1.5 \mathrm{nM}$ $[\mathrm{N}+\mathrm{N}]$ (Table 1). The practical limit of detection is $1 \mathrm{nM}$, below which no peaks are observed. Using $\mathrm{Fe}(\mathrm{II})+\mathrm{Mo}(\mathrm{VI})$ as a reducing agent, Dore and Karl (1996) report precision of [N+N] to be $\pm 0.5 \mathrm{nM}$ at concentrations below $50 \mathrm{nM}$ and $\pm 1.6 \%$ at concentrations above $50 \mathrm{nM}$, in good agreement with our findings.

Accuracy and reproducibility was determined using the $40.0 \mu \mathrm{M}$ Wako CSK standard nitrate solution diluted to concentrations of $4 \mathrm{nM}, 16 \mathrm{nM}$ and $160 \mathrm{nM}$ nitrate (Table 1; Figure 4). Over the course of 14 different days, the averages $( \pm 1 \sigma)$ are $4.1 \pm 0.29 \mathrm{nM}(\mathrm{n}=30), 15.9 \pm 0.64$ $\mathrm{nM}(\mathrm{n}=36)$ and $158.6 \pm 2.55 \mathrm{nM}(\mathrm{n}=34)$. These values are nearly identical to 5-year averages from the HOT quality control charts using Fe(II)+Mo(VI) as a reducing agent with Wako CSK concentrations also at $4 \mathrm{nM}, 16 \mathrm{nM}$ and $160 \mathrm{nM}$ nitrate: $4.09 \pm 0.50 \mathrm{nM}(\mathrm{n}=60), 15.88 \pm 0.94 \mathrm{nM}$ $(\mathrm{n}=65)$ and $156.93 \pm 4.51 \mathrm{nM}(\mathrm{n}=60)(\mathrm{http} / /$ hahana.soest.hawaii.edu/hot/methods/llnuts.html).

\subsection{Sample Comparison}

To directly compare the Ti reducing agent to the (Fe+Mo) reducing agent, samples and reference standards were analyzed by each method on the same day, using the same calibration standards, same sulfuric acid and same CL nitrogen detector (Table 2; Figure 5).

Using undiluted $\mathrm{TiCl}_{3}, 28$ seawater samples and 8 standards were compared. At $[\mathrm{N}+\mathrm{N}]$ values less than $10 \mathrm{nM}$, the average difference (Ti-(Fe+Mo)) is $-0.3 \mathrm{nM} \pm 0.4 \mathrm{nM}$, with 12 out of 16 points being negative. At $[\mathrm{N}+\mathrm{N}]$ values $>10 \mathrm{nM}$, the average ratio $(\mathrm{Ti} /(\mathrm{Fe}+\mathrm{Mo})$ is $0.99 \pm 0.04$ $(n=19)$ with one outlier removed (SW sample 2-32-6). Figure 5 displays the excellent agreement between the two methods at high concentrations but a bias toward low values from the Ti(III) method at low concentrations; however, the Ti(III) method produced more accurate results for 6 out of the 8 reference standards, including those at $4 \mathrm{nM}[\mathrm{N}+\mathrm{N}]$ (Table 2). Using a Model II, Least-Squares-Cubic linear regression, with error defined by the repeatability curve (Figure 3), the line through the "undiluted" data points of Figure 5 is: $1.019( \pm 0.007) \mathrm{x}+0.16( \pm 0.16)$. 
Using diluted $\mathrm{TiCl}_{3}, 13$ seawater samples and 4 standards were used to compare the two reducing agents (Table 2; Figure 5). Although it is a smaller dataset than the one using undiluted $\mathrm{TiCl}_{3}$, there seems to be improved agreement between the two reducing agents: the average difference $(\mathrm{Ti}-(\mathrm{Fe}+\mathrm{Mo})$ ) for $[\mathrm{N}+\mathrm{N}]$ values $<10 \mathrm{nM}$, is $0.3 \mathrm{nM} \pm 0.3 \mathrm{nM}$ (with one outlier removed, sample 2-38-8), and the average ratio $(\mathrm{Ti} /(\mathrm{Fe}+\mathrm{Mo})$ for $[\mathrm{N}+\mathrm{N}]$ values $>10 \mathrm{nM}$ ranges only from 0.98-1.01 $(\mathrm{n}=7)$. The regression line through the "diluted" data points of Figure 5 is: $1.012( \pm 0.006) \mathrm{x}-0.25( \pm 0.16)$, suggesting a very slight bias to higher values at low concentrations. However, overall, the two methods agree to within reproducibility limits or better.

Colorimetric analyses on 15 of the seawater samples, ranging in concentration from 35$1080 \mathrm{nM}[\mathrm{N}+\mathrm{N}]$, show remarkable agreement with the CL data overall. Using Ti(III) chemistry, agreement averages $98 \% \pm 4 \%(1 \sigma)$; using $\mathrm{Fe}(\mathrm{II})+\mathrm{Mo}(\mathrm{VI})$ chemistry, agreement averages $99 \% \pm$ $6 \%(1 \sigma)$.

\subsection{Future applications of the Ti(III) chemistry}

\subsubsection{Direct determination of Dissolved Organic Nitrogen (DON)}

Attempts to establish a method for the direct determination of DON in seawater have been met with various obstacles, to the point that DON is still typically reported as the difference between total dissolved nitrogen (TDN) and dissolved inorganic nitrogen (DIN: [N+N] plus ammonium) (see review by Sipler and Bronk, 2015). This approach works relatively well in the ocean's uppermost water column, since TDN is a significantly larger number than DIN (in most cases), leading to tolerable error estimates on DON values. As water deepens, DIN accounts for more and more of the TDN, resulting in intolerable errors and sometimes even negative values for DON (e.g. Hansell, 1993; Sharp et al., 2002). A direct method to quantify DON is needed in order to establish a reliable mass balance of nitrogen in the lower $\sim 80 \%$ of the open ocean.

A protocol for the direct determination of DON, is, by necessity, two-fold. The first step is to eliminate DIN from the seawater sample, with $[\mathrm{N}+\mathrm{N}]$ being by far the most abundant component. The second step is to convert the many unique DON compounds into a single, measurable species of nitrogen, as is done with traditional TDN analyses (Sipler and Bronk, 2015). Various pretreatment methods have been explored to remove DIN, including membrane methods such as dialysis and nanofiltration, adsorptive methods such as ion exchange and size- 
exclusion chromatography, as well as palladium-based catalytic reduction of $[\mathrm{N}+\mathrm{N}]$ (Chen et al., 2015 and references therein). These pretreatment methods either do not remove all $[\mathrm{N}+\mathrm{N}]$ or show procedural gains or losses of DON, with seawater being overall more problematic than freshwater; therefore, these are not reliable and have not been adopted for routine analysis of natural water samples.

Total Kjeldahl nitrogen (TKN) is a method for the determination of organic nitrogen content that has been applied extensively to foodstuffs as well as wastewater following its inception in 1883 (Kjeldahl, 1883; Sáez-Plaza et al., 2013). It entails a sulfuric acid digestion that generates ammonium as a mineralization product, and at first glance, would seem ideally applied to natural waters since $[\mathrm{N}+\mathrm{N}]$ is essentially "invisible." However, it is generally acknowledged that DON recovery is uniformly low in the presence of high $[\mathrm{N}+\mathrm{N}]$ to DON ratios (Sáez-Plaza et al., 2013). Fraga (1959) presented a modified Kjeldahl method in which nitrate, nitrite and ammonium are all eliminated before digestion, thereby providing a truly direct (and interference-free) analysis of DON. Although the Fraga method was applied to upper ocean water in a number of locations (Fraga, 1966; Doval et al., 1997; Doval et al., 1999), the method was not widely adopted, possibly because cumulative reagent blanks are quite high $(2 \mu \mathrm{M} \mathrm{N}$; Doval et al., 1997; Doval et al., 1999) and of a similar concentration to deep ocean samples (e.g. Karl et al., 2001) where a direct determination is needed most.

Here, we follow-up on an insightful recommendation from the DON subgroup report (Hopkinson et al., 1993) to modify the reduction chemistry validated by Cox (1980) and Garside (1982) and apply it to a method for the direct quantification of DON. Of course, using the standard $\mathrm{Fe}(\mathrm{II})+\mathrm{Mo}(\mathrm{IV})$ reduction chemistry succeeds in purging $[\mathrm{N}+\mathrm{N}]$, but makes the quantification of DON completely unattainable due to overwhelming ammonium contamination. By using $\mathrm{TiCl}_{3},[\mathrm{~N}+\mathrm{N}]$ could be purged from the samples (in the form of $\mathrm{NO}$ gas), leaving only DON and original $\mathrm{NH}_{4}{ }^{+}$, with minimal contamination. Our preliminary results indicate that 40 $\mu \mathrm{M}$ of nitrate in seawater (both artificially spiked and in natural, deep seawater) can be converted to $\mathrm{NO}$ by pre-treating the seawater with only $0.06 \% \mathrm{TiCl}_{3}(\mathrm{w} / \mathrm{v}$ in the sample) and heating to $80^{\circ} \mathrm{C}$ in an oven (no addition of sulfuric acid); samples treated in this way have resulting $[\mathrm{N}+\mathrm{N}]$ values that fall near the detection limit of the $\mathrm{CL}$ method (i.e. $\sim 1 \mathrm{nM}$ ). Once $[\mathrm{N}+\mathrm{N}]$ is eliminated, the sample can be analyzed for remaining TDN (now equal to DON + $\mathrm{NH}_{4}{ }^{+}$) with one of the conventional methods: high-temperature combustion, wet chemical 
oxidation, or ultraviolet oxidation. This shows great promise in the quest for a direct DON measurement, but additional work is needed to validate that the organic fraction of nitrogen is completely preserved. Also, ammonium would need to be measured, purged separately under alkaline conditions, or alternatively, be included in the DON measurement for a quantification of "reduced nitrogen."

\subsubsection{Determination of $[N+N]$ in complex fluids}

The quantification of nitrite and nitrate is profoundly important for characterizing not only natural waters, but also substances ranging from food and beverages to biological fluids. Each substance is unique in terms of its matrix complications, method-dependent interferences, required accuracy and detection limits. The only method that competes with the CL method's low detection limit is through using liquid waveguide capillary cells coupled to the spectrographic method (e.g. Yao et al., 1998; Patey et al., 2008), but it is subject to the normal drawbacks of traditional colorimetry, including sensitivity to matrix and $\mathrm{pH}$, and a general intolerance to sample color or cloudiness. These drawbacks do not apply to the CL method, hence it has been adopted for biological fluids, such as blood, urine and plasma, starting with the work of Cox \& Frank (1982). The CL method has the potential to be more widely applied to a myriad of other commonly analyzed materials such as foods, wine and soils (see Moorcroft et al., 2001). The Ti(III) chemistry is an easier system to use than the more popular Fe(II)+Mo(IV) chemistry for the simple fact there is only one reducing reagent; it is also appealing compared to the use of the more toxic V(III) reducing agent (Braman and Hendrix, 1989), and therefore has the potential to become the chemistry of choice.

\section{Conclusions}

The reducing agent $\mathrm{Fe}(\mathrm{II})+\mathrm{Mo}(\mathrm{IV})$ (via ferrous ammonium sulfate and ammonium molybdate) has been used in the CL detection of $[\mathrm{N}+\mathrm{N}]$ in seawater since the early 1980's (e.g. Garside, 1982; Dore and Karl, 1996; Lipschultz, 2001). Here we have validated the use of the Ti(III) reducing agent for seawater analyses, which has a number of benefits over the use of $\mathrm{Fe}(\mathrm{II})+\mathrm{Mo}(\mathrm{IV})$, and yields identical precision, accuracy, detection limit and sample results.

Undoubtedly, the greatest benefit of the Ti(III) reduction chemistry is that it does not contain ammonium. As ammonium receives more and more attention for being an important 
part of the marine nitrogen cycle (see Francis et al., 2007, for a helpful review), there is increasing interest in being able to measure its very low concentrations in seawater. One overarching challenge to this is the fact that ammonium $\left(\mathrm{NH}_{4}{ }^{+}\right)$can volatilize as ammonia $\left(\mathrm{NH}_{3}\right)$, adsorb onto exposed surfaces, and cause widespread contamination of a laboratory. Because laboratory groups who are interested in measuring $[\mathrm{N}+\mathrm{N}]$ are likely to also be interested in measuring ammonium, it is useful to have a $[\mathrm{N}+\mathrm{N}]$ method that will not contaminate the analytical environment. Potentially even more significant is that by using Ti(III) to purge [N+N] from a water sample, the remaining DON pool could be quantified after oxidation to nitrate.

Additional benefits of using Ti(III) include: (1) the Ti(III) method has been optimized using 30\% less concentrated sulfuric acid than the Fe(II)+Mo(IV) method, thereby increasing cost-effectiveness, and (2) if using sulfuric acid with no background [N+N], sample run time can be decreased because there is no waiting period for purging reagent blanks, hence increasing sample through-put.

\section{Acknowledgements}

We thank Susan Curless, Alexa Nelson, Sara Ferrón, Benedetto Barone, Stuart Goldberg, Brenner Wai and Matthew Church for their generosity of laboratory and/or intellectual support. We also acknowledge the contributions of John E. Dore to our lab group two decades ago, which laid the foundation for the analytical work used in this study. This research was supported in part by the Gordon and Betty Moore Foundation's Marine Microbiology Initiative (grant \#3794 to DMK), the Simons Foundation via the Simons Collaboration on Ocean Processes and Ecology (SCOPE to DMK) and the National Science Foundation (C-MORE, DBI-0424599 to DMK and OCE-1260164 to MC and DMK). 


\section{References}

Aoki, T., Fukuda, S., Hosoi, Y., Mukai, H., 1997. Rapid flow injection analysis method for successive determination of ammonia, nitrite, and nitrate in water by gas-phase chemiluminescence. Anal. Chim. Acta 349, 11-16. doi:10.1016/S0003-2670(97)00273-0

Aoki, T., Wakabayashi, M., 1995. Simultaneous flow injection determination of nitrate and nitrite in water by gas-phase chemiluminescence. Anal. Chim. Acta 308, 308-312. doi:10.1016/00032670(94)00603-J

Awad, W., Hassan, S.S.M., 1969. Microdetermination of nitrates and nitramines-I Titrimetric methods based on the reduction with iron(II), titanium(III), and a mixture of both. Talanta 16, 1383-1391. doi:10.1016/0039-9140(69)80180-3

Braman, R.S., Hendrix, S. a, 1989. Nanogram nitrite and nitrate determination in environmental and biological materials by vanadium (III) reduction with chemiluminescence detection. Anal. Chem. 61, 2715-2718. doi:10.1021/ac00199a007

Chen, B., Westerhoff, P., Zhang, L., Zhu, A., Yang, X., Wang, C., 2015. Application of Pretreatment Methods for Reliable Dissolved Organic Nitrogen Analysis in Water-A Review. Crit. Rev. Environ. Sci. Technol. 45, 249-276. doi:10.1080/10643389.2013.852400

Cox, R.D., 1980. Determination of nitrate and nitrite at the parts per billion level by chemiluminescence. Anal. Chem. 52, 332-335. doi:10.1021/ac50052a028

Cox, R.D., Frank, C.W., 1982. Determination of nitrate and nitrite in blood and urine by chemiluminescence. J. Anal. Toxicol. 6, 148-152.

Dore, J.E., Karl, D.M., 1996. Nitrite distributions and dynamics at Station ALOHA. Deep Sea Res. Part II Top. Stud. Oceanogr. 43, 385-402.

Doval, M., Perez, F.F., Berdalet, E., 1999. Dissolved and particulate organic carbon and nitrogen in the Northwestern Mediterranean. Deep Sea Res. Part I Oceanogr. Res. Pap. 46, 511-527. doi:10.1016/S0967-0637(98)00072-7

Doval, M.D., Fraga, F., Perez, F.F., 1997. Determination of dissolved organic nitrogen in seawater using Kjeldahl digestion after inorganic nitrogen removal. Oceanol. Acta 20, 713-720.

Fraga, F., 1966. Distribution of particulate and dissolved nitrogen in the Western Indian ocean. Deep Sea Res. 13, 413-425.

Fraga, F., 1959. Determinación nitrógeno orgánico suspendido y disuelto en agua de mar. Investig. Pesq. $14,121-127$.

Francis, C.A., Beman, J.M., Kuypers, M.M.M., 2007. New processes and players in the nitrogen cycle: the microbial ecology of anaerobic and archaeal ammonia oxidation. ISME J. 1, 19-27. doi:10.1038/ismej.2007.8 
Garcia, H. E., Locarnini, R.A., Boyer, T.P., Antonov, J.I., Baranova, O.K., Zweng, M.M., Reagan, J.R., Johnson, D.R., 2014. World Ocean Atlas 2013, Volume 4: Dissolved Inorganic Nutrients (phosphate, nitrate, silicate). S. Levitus, Ed., A. Mishonov Technical Ed.; NOAA Atlas NESDIS 76, $25 \mathrm{pp}$.

Garside, C., 1982. A chemiluminescent technique for the determination of nanomolar concentrations of nitrate and nitrite in seawater. Mar. Chem. 11, 159-167. doi:http://dx.doi.org/10.1016/03044203(82)90039-1

Hansell, D.A., 1993. Results and observations from the measurement of DOC and DON in seawater using a high-temperature catalytic oxidation technique. Mar. Chem. 41, 195-202.

doi:http://dx.doi.org/10.1016/0304-4203(93)90119-9

Holmes, R.M., Aminot, A., Kerouel, R., Hooker, B.A., Peterson, B.J., 1999. A simple and precise method for measuring ammonium in marine and freshwater ecosystems. Can. J. Fish. Aquat. Sci. 56, 18011808. doi:10.1139/cjfas-56-10-1801

Hopkinson, C., Cifuentes, L., Burdige, D., Fitzwater, S., Hansell, D., Henrichs, S., Kähler, P., Koike, I., Walsh, T., Bergamaschi, B., 1993. Measurement of Dissolved Organic Carbon and Nitrogen in Natural Waters DON subgroup report. Mar. Chem. 41, 23-36. doi:http://dx.doi.org/10.1016/03044203(93)90103-U

Karl, D.M., Björkman, K.M., Dore, J.E., Fujieki, L., Hebel, D. V, Houlihan, T., Letelier, R.M., Tupas, L.M., 2001. Ecological nitrogen-to-phosphorus stoichiometry at station ALOHA. Deep Sea Res. Part II Top. Stud. Oceanogr. 48, 1529-1566. doi:http://dx.doi.org/10.1016/S0967-0645(00)00152-1

Kjeldahl, J.Z., 1883. Neue Methode zur Bestimmung des Stickstoffs im organishen Korpern. Z. Anal. Chem. 22, 366-382.

Lipschultz, F., 2001. A time-series assessment of the nitrogen cycle at BATS. Deep. Res. Part II Top. Stud. Oceanogr. 48, 1897-1924. doi:10.1016/S0967-0645(00)00168-5

Moorcroft, M., Davis, J., Compton, R.G., 2001. Detection and determination of nitrate and nitrite: a review. Talanta 54, 785-803. doi:10.1016/S0039-9140(01)00323-X

Patey, M.D., Rijkenberg, M.J.A., Statham, P.J., Stinchcombe, M.C., Achterberg, E.P., Mowlem, M., 2008. Determination of nitrate and phosphate in seawater at nanomolar concentrations. TrAC Trends Anal. Chem. 27, 169-182. doi:http://dx.doi.org/10.1016/j.trac.2007.12.006

Sáez-Plaza, P., Michałowski, T., Navas, M.J., Asuero, A.G., Wybraniec, S., 2013. An overview of the Kjeldahl method of nitrogen determination. Part I. Early history, chemistry of the procedure, and titrimetric finish. Crit. Rev. Anal. Chem. 43, 178-223.

Segura-Noguera. M, Cruzado, A., Blasco, D., 2011. Nutrient preservation, analysis precision and quality control of an oceanographic database of inorganic nutrients, dissolved oxygen and chlorophyll a 
from the NW Mediterranean Sea. Sci. Mar. 75(2): 321-339. Sci. Mar. 75, 321-339.

Sharp, J.H., Rinker, K.R., Savidge, K.B., Abell, J., Yves, J., Bronk, D., Burdige, D.J., Cauwet, G., Chen, W., Doval, M.D., Hansell, D., Hopkinson, C., Kattner, G., Kaumeyer, N., Mcglathery, K.J., Merriam, J., Morley, N., Nagel, K., Ogawa, H., Pollard, C., Pujo-pay, M., Raimbault, P., Sambrotto, R., Seitzinger, S., Spyres, G., Tirendi, F., Walsh, T.W., Wong, C.S., 2002. A preliminary methods comparison for measurement of dissolved organic nitrogen in seawater. Mar. Chem. 78, 171-184.

Sipler, R.E., Bronk, D.A., 2015. Dynamics of Dissolved Organic Nitrogen, in: Hansell, D.A., Carlson, C.A. (Eds.), Biogeochemistry of Marine Dissolved Organic Matter. pp. 127-232. doi:http://dx.doi.org/10.1016/B978-0-12-405940-5.00004-2

Strickland, J.D.H., Parsons, T.R., 1972. A Practical Handbook of Seawater Analysis. Bull. Fish. Res. Board Canada 167, 71-80.

Yang, F., Troncy, E., Francœur, M., Vinet, B., Vinay, P., Czaika, G., Blaise, G., 1997. Effects of reducing reagents and temperature on conversion of nitrite and nitrate to nitric oxide and detection of NO by chemiluminescence. Clin. Chem. 43, 657-662.

Yao, W., Byrne, R.H., Waterbury, R.D., 1998. Determination of nanomolar concentrations of nitrite and nitrate in natural waters using long path length absorbance spectroscopy. Environ. Sci. Technol. 32, 2646-2649. doi:10.1021/es9709583

Zhu, Y., Yuan, D., Huang, Y., Ma, J., Feng, S., Lin, K., 2014. A modified method for on-line determination of trace ammonium in seawater with a long-path liquid waveguide capillary cell and spectrophotometric detection. Mar. Chem. 162, 114-121. doi:10.1016/j.marchem.2014.03.011 
Table 1. Method Precision Data

\begin{tabular}{|c|c|c|c|c|}
\hline \multicolumn{5}{|c|}{ Repeatability ${ }^{a}$} \\
\hline Sample & Average $\mathrm{N}+\mathrm{N}(\mathrm{nM})$ & Std dev (nM) & Std dev (\%) & $\mathrm{n}$ \\
\hline $2 \mathrm{nM} \mathrm{KNO}_{3}$ & 2.2 & 0.15 & $6.7 \%$ & 10 \\
\hline 4nM CSK & 4.4 & 0.25 & $5.7 \%$ & 10 \\
\hline 16nM CSK & 15.2 & 0.36 & $2.4 \%$ & 12 \\
\hline $20 \mathrm{nM} \mathrm{KNO}_{3}$ & 20.0 & 0.3 & $1.5 \%$ & 9 \\
\hline 160nM CSK & 156.5 & 0.96 & $0.6 \%$ & 12 \\
\hline $1000 \mathrm{nM} \mathrm{KNO}_{3}$ & 999.8 & 4.7 & $0.5 \%$ & 13 \\
\hline KM1409-2-24-16 & 3.4 & 0.14 & $4.1 \%$ & 12 \\
\hline KM1409-2-29-4 & 47.1 & 0.63 & $1.3 \%$ & 12 \\
\hline KM1409-2-24-2 & 582.3 & 2.82 & $0.5 \%$ & 12 \\
\hline KM1409-2-29-2 & 812.9 & 2.50 & $0.3 \%$ & 8 \\
\hline \multicolumn{5}{|c|}{ Long-term Accuracy and Reproducibility ${ }^{b}$} \\
\hline Sample & $\begin{array}{c}\text { Average } \mathrm{N}+\mathrm{N} \\
(\mathrm{nM})\end{array}$ & Std dev (nM) & Std dev (\%) & $\mathrm{n}$ \\
\hline 4nM CSK & 4.1 & 0.29 & $7.1 \%$ & 30 \\
\hline 16nM CSK & 15.9 & 0.64 & $4.0 \%$ & 36 \\
\hline 160nM CSK & 158.6 & 2.55 & $1.6 \%$ & 34 \\
\hline
\end{tabular}

${ }^{a}$ Repeatability was determined by replicate measurement of the same sample/standard on the same day. CSK refers to the Wako CSK Nitrate Standard. KNO3 and CSK dilutions were prepared in DI water. Seawater samples are natural, and not artificially spiked with nitrate.

${ }^{\mathrm{b}}$ Reproducibility was determined from results for the Wako CSK Standard Nitrate solution diluted to 4, 16 and $160 \mathrm{nM}$ collected over the course of 10 days. Data points from the repeatability determination were averaged into a single data point for the calculation of accuracy and reproducibility. 
Table 2. Comparison of results using $\mathrm{Ti}(\mathrm{III})$ versus $\mathrm{Fe}(\mathrm{II})+\mathrm{Mo}(\mathrm{VI})$ reducing agents.

\begin{tabular}{|c|c|c|c|c|c|}
\hline \multirow[b]{2}{*}{ Sample } & \multicolumn{3}{|c|}{$\begin{array}{c}\text { Nitrate + Nitrite Concentrations } \\
\text { (nM) }\end{array}$} & \multirow[b]{2}{*}{$\mathrm{Ti} /(\mathrm{Fe}+\mathrm{Mo})$} & \multirow[b]{2}{*}{$\mathrm{Ti}-(\mathrm{Fe}+\mathrm{Mo})$} \\
\hline & $\mathrm{Ti}(\mathrm{III})$ & $\mathrm{Fe}(\mathrm{II})+\mathrm{Mo}(\mathrm{VI})$ & $A A^{a}$ & & \\
\hline \multicolumn{6}{|l|}{ Day 1, Undiluted $\mathrm{TiCl}_{3}{ }^{b}$} \\
\hline $2-20-12^{c}$ & 3.6 & 3.8 & & 0.96 & -0.2 \\
\hline 4nM CSK & 4.4 & 4.9 & & 0.91 & -0.4 \\
\hline $2-17-13$ & 5.8 & 5.7 & & 1.01 & 0.1 \\
\hline 16nM CSK & 16.4 & 16.3 & & 1.01 & 0.1 \\
\hline $2-32-6$ & 16.5 & 13.8 & & 1.20 & 2.7 \\
\hline $2-29-6$ & 18.2 & 18.9 & & 0.96 & -0.7 \\
\hline $2-29-4$ & 43.8 & 46.0 & & 0.95 & -2.2 \\
\hline $2-32-4$ & 137.7 & 145.2 & 141 & 0.95 & -7.5 \\
\hline 160nM CSK & 153.8 & 151.6 & & 1.01 & 2.2 \\
\hline 2-17-7 & 223.6 & 234.7 & 226 & 0.95 & -11.2 \\
\hline $2-17-5$ & 245.5 & 258.7 & 263 & 0.95 & -13.2 \\
\hline $2-17-3$ & 335.2 & 356.2 & 350 & 0.94 & -20.9 \\
\hline $2-4-4$ & 531.5 & 533.4 & 531 & 1.00 & -1.9 \\
\hline \multicolumn{6}{|l|}{ Day 2, Undiluted $\mathrm{TiCl}_{3}$} \\
\hline $2-10-11$ & 1.2 & 1.2 & & 1.04 & 0.0 \\
\hline $2-10-17$ & 1.6 & 2.3 & & 0.69 & -0.7 \\
\hline $2-10-15$ & 1.7 & 1.8 & & 0.91 & -0.2 \\
\hline $2-10-19$ & 1.9 & 2.2 & & 0.89 & -0.2 \\
\hline $2-10-13$ & 2.0 & 2.5 & & 0.82 & -0.5 \\
\hline $2-24-16$ & 2.3 & 2.8 & & 0.82 & -0.5 \\
\hline $2-10-9$ & 2.8 & 3.2 & & 0.88 & -0.4 \\
\hline $2-24-14$ & 3.7 & 4.4 & & 0.84 & -0.7 \\
\hline $2-24-6$ & 3.8 & 3.6 & & 1.06 & 0.2 \\
\hline $2-24-8$ & 3.9 & 3.1 & & 1.25 & 0.8 \\
\hline 4nM CSK & 4.2 & 4.6 & & 0.92 & -0.4 \\
\hline $2-24-12$ & 4.2 & 4.9 & & 0.86 & -0.7 \\
\hline $2-24-10$ & 4.8 & 5.3 & & 0.91 & -0.5 \\
\hline 16nM CSK & 15.7 & 15.2 & & 1.04 & 0.6 \\
\hline 20nM OSIL Nitrite & 18.6 & 19.7 & & 0.94 & -1.1 \\
\hline 2-10-7 & 35.3 & 32.2 & 39 & 1.10 & 3.1 \\
\hline $2-10-5$ & 82.4 & 83.6 & 79 & 0.99 & -1.2 \\
\hline $2-24-4$ & 105.4 & 110.3 & 111 & 0.96 & -4.8 \\
\hline 160nM CSK & 159.1 & 155.2 & & 1.02 & 3.8 \\
\hline 200nM OSIL Nitrite & 200.4 & 190.0 & & 1.06 & 10.5 \\
\hline High Nitrite SW ${ }^{d}$ & 365.2 & 368.7 & 370 & 0.99 & -3.5 \\
\hline $2-24-2$ & 536.7 & 556.6 & 547 & 0.96 & -19.9 \\
\hline $2-10-3$ & 851.0 & 858.7 & 843 & 0.99 & -7.6 \\
\hline
\end{tabular}


Table 2 (continued). Comparison of results using $\mathrm{Ti}(\mathrm{III})$ versus $\mathrm{Fe}(\mathrm{II})+\mathrm{Mo}(\mathrm{VI})$ reducing agents.

\begin{tabular}{|c|c|c|c|c|c|}
\hline \multirow[b]{2}{*}{ Sample } & \multicolumn{3}{|c|}{ Nitrate + Nitrite Concentrations (nM) } & \multirow[b]{2}{*}{$\mathrm{Ti} /(\mathrm{Fe}+\mathrm{Mo})$} & \multirow[b]{2}{*}{ Ti-(Fe+Mo) } \\
\hline & $\mathrm{Ti}(\mathrm{III})$ & $\mathrm{Fe}(\mathrm{II})+\mathrm{Mo}(\mathrm{VI})$ & $A A^{a}$ & & \\
\hline \multicolumn{6}{|l|}{ Day 3, Diluted $\mathrm{TiCl}_{3}{ }^{e}$} \\
\hline $2-44-14$ & 2.4 & 2.2 & & 1.09 & 0.2 \\
\hline $2-44-10$ & 2.8 & 2.5 & & 1.14 & 0.4 \\
\hline $2-44-8$ & 3.3 & 3.0 & & 1.08 & 0.3 \\
\hline $2-44-12$ & 3.3 & 3.2 & & 1.03 & 0.1 \\
\hline $2-38-14$ & 3.8 & 3.6 & & 1.06 & 0.2 \\
\hline 4nM CSK & 3.9 & 3.5 & & 1.11 & 0.4 \\
\hline $2-38-10$ & 4.7 & 4.0 & & 1.17 & 0.7 \\
\hline $2-38-12$ & 4.8 & 4.0 & & 1.21 & 0.8 \\
\hline $2-44-6$ & 5.8 & 6.0 & & 0.98 & -0.1 \\
\hline $2-38-8$ & 6.5 & 8.7 & & 0.74 & -2.2 \\
\hline 16nM CSK & 15.1 & 14.9 & & 1.01 & 0.1 \\
\hline 40nM CSK Nitrite & 39.2 & 38.8 & & 1.01 & 0.4 \\
\hline 160nM CSK & 159.3 & 158.6 & & 1.00 & 0.7 \\
\hline $2-38-4$ & 183.4 & 183.3 & 205 & 1.00 & 0.1 \\
\hline $2-44-4$ & 340.4 & 339.0 & 355 & 1.00 & 1.4 \\
\hline $2-38-2$ & 908.3 & 925.4 & 888 & 0.98 & -17.1 \\
\hline $2-44-2$ & 1080.3 & 1095.7 & 1060 & 0.99 & -15.3 \\
\hline
\end{tabular}

${ }^{\mathrm{a}}$ Auto-Analyzer results for comparison to both $\mathrm{CL}$ methods.

${ }^{b}$ All samples labeled 2-xx-xx are seawater samples from Station ALOHA

${ }^{c}$ Reducing reagents consist of $6 \mathrm{~mL}$ concentrated sulfuric acid and $1 \mathrm{~mL} 20 \% \mathrm{TiCl}_{3}$.

${ }^{\mathrm{d}}$ Seawater with $331 \mathrm{nM}$ nitrite, as confirmed by a Liquid Waveguide Capillary Cell method.

${ }^{\mathrm{e}}$ Reducing reagents consist of $7 \mathrm{~mL}$ concentrated sulfuric acid and $2 \mathrm{~mL}$ of $4 \% \mathrm{TiCl}_{3}$. 

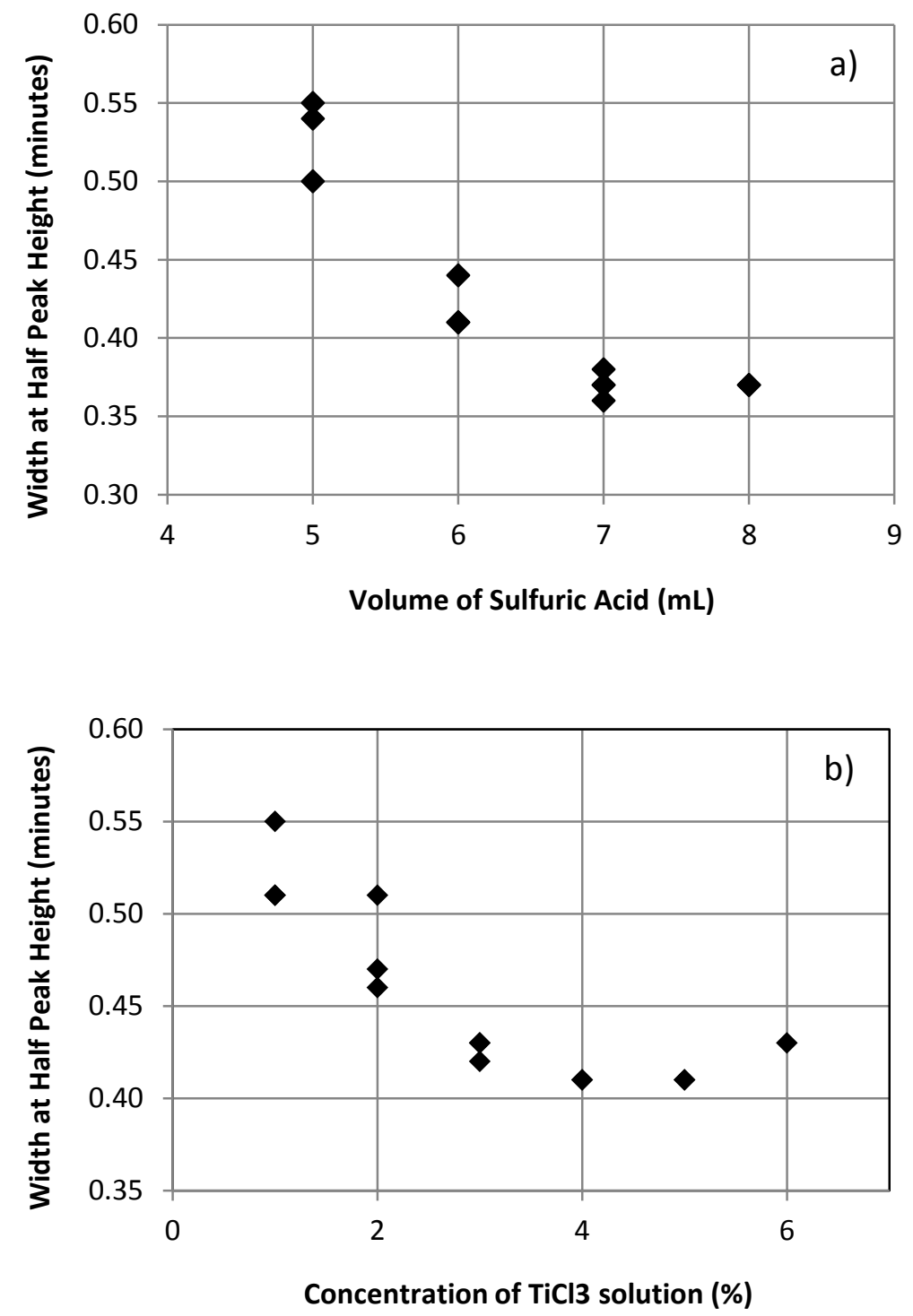

Figure 1. Plots showing optimization tests for determining the volume of concentrated sulfuric acid and concentration of the $\mathrm{TiCl}_{3}$ reagent to be used for a $10 \mathrm{~mL}$ sample injection. In the top panel, sulfuric acid volume varied while keeping the $\mathrm{Ti}(\mathrm{III})$ reagent at $2 \mathrm{~mL}$ of $5 \%(\mathrm{w} / \mathrm{v}) \mathrm{TiCl}_{3}$. In the bottom panel, the volume of sulfuric acid was set to $7 \mathrm{~mL}$ while varying the concentration of $\mathrm{TiCl}_{3}$ used. 


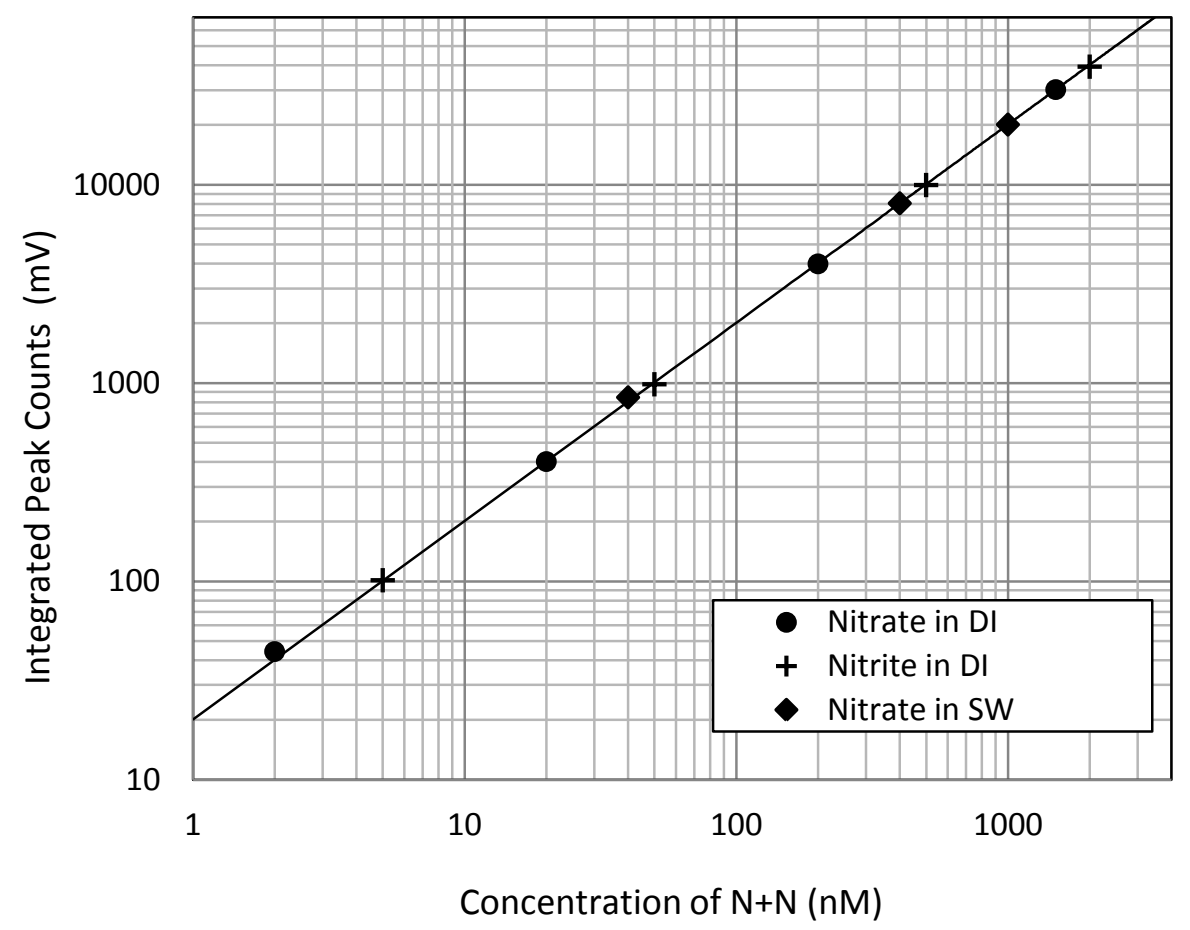

Figure 2. Calibration curve for the $\mathrm{CL}$ detection of nitrate and nitrite. Chemiluminescent response in terms of peak count is identical for nitrate or nitrite as well as if the standard is prepared in de-ionized water (DI) or surface seawater (SW). The seawater points are corrected for $2.8 \mathrm{nM}$ background nitrate. 


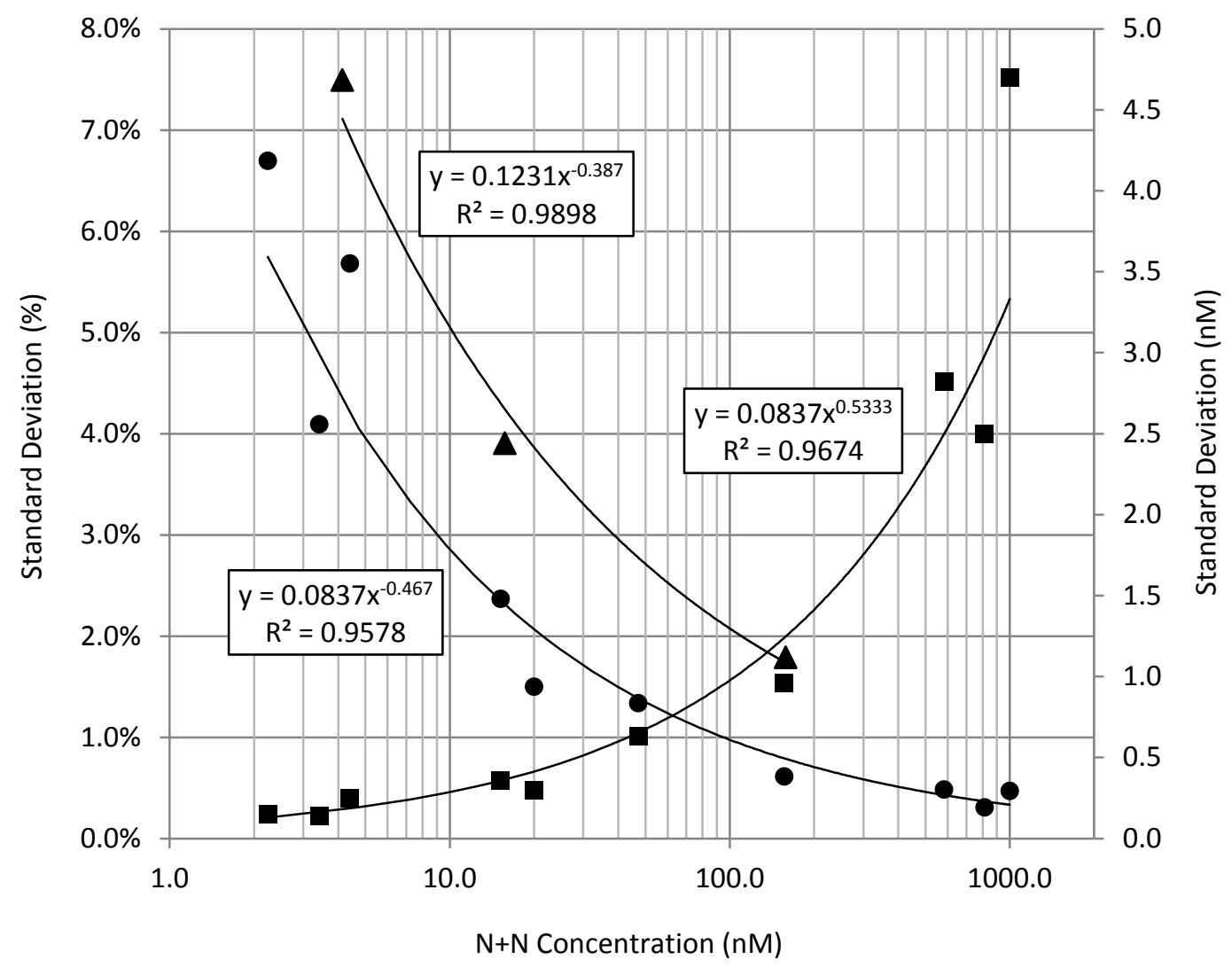

Figure 3. Repeatability of standards $(n=6)$ and seawater samples $(n=4)$ in terms of concentration ( $\mathbf{a})$ or percentage $(\bullet)$, and reproducibility of the Wako CSK reference standard in terms of percentage $(\boldsymbol{\Delta})$. Curves are one-error power law regressions. 

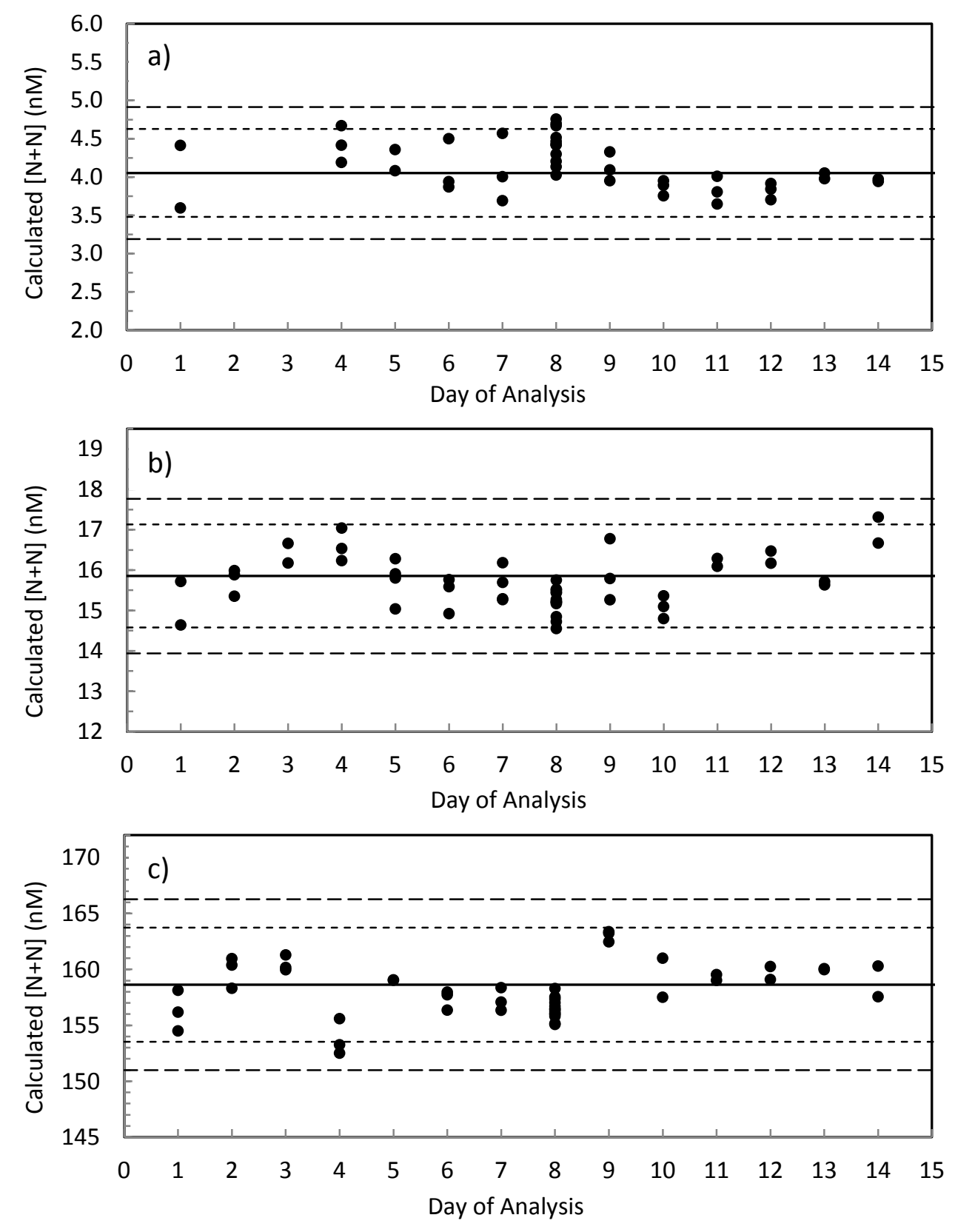

Figure 4. WAKO Nitrate CSK Quality Control Charts for concentrations of a) $4 \mathrm{nM}$, b) $16 \mathrm{nM}$ and c) $160 \mathrm{nM} \mathrm{KNO}_{3}$ over the course of 14 days. The averages $( \pm 1 \sigma)$ are $4.1 \mathrm{nM} \pm 0.3(n=30), 15.9 \mathrm{nM} \pm 0.6(n=36)$ and $158.6 \mathrm{nM} \pm 2.6$ $(n=34)$. Short dashed lines are $2 \sigma$ warning limits and long dashed lines are $3 \sigma$ control limits. 


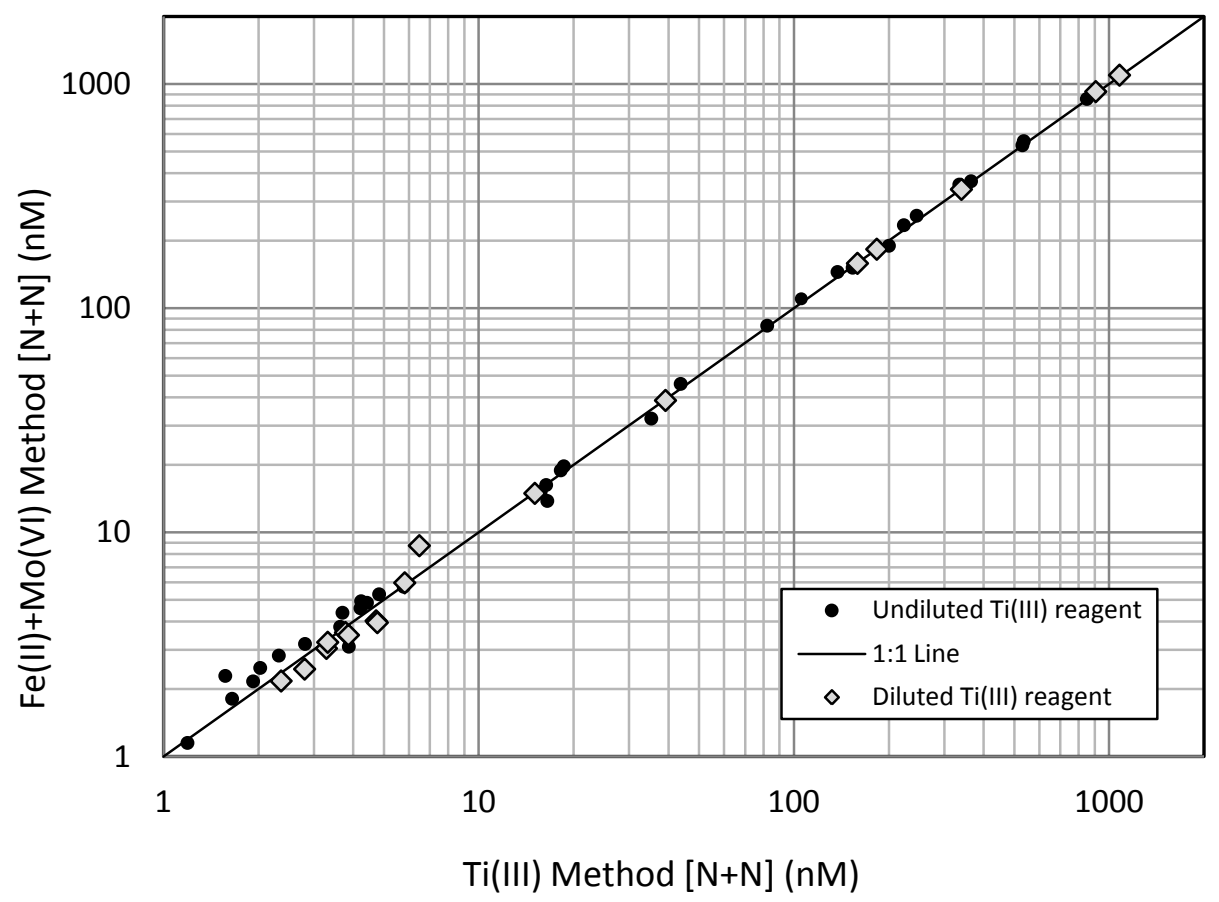

Figure 5. Comparison of reducing agents in the $\mathrm{CL}$ detection of nitrate and nitrite. Data points include Wako CSK nitrate standards $(n=9)$, Wako CSK and OSIL nitrite standards $(n=3)$, and seawater samples $(n=41)$ from station ALOHA, north of Oahu, Hawaii, USA. Ti(III) reducing reagents for the data series labeled "Undiluted Ti(III)" are $6 \mathrm{~mL}$ concentrated sulfuric acid and $1 \mathrm{~mL} 20 \% \mathrm{TiCl}_{3}$. Ti(III) reducing reagents for the data series labeled "Diluted Ti(III)" are $7 \mathrm{~mL}$ concentrated sulfuric acid and $2 \mathrm{~mL}$ of $4 \% \mathrm{TiCl}_{3}$. 